\title{
Compositional Design of Glasses with Large Second- and Third-Order Optical Nonlinearity
}

\author{
Hiroyuki NASU \\ Department of Chemistry for Materials, Faculty of Engineering, Mie University, 1515, Kamihama-cho, Tsu-shi 514-8507
}

\author{
大きな二次及び三次の非線形効果をもつガラスの組成設計 \\ 那須弘行 \\ 三重大学工学部分子素材工学科, 514-8507 津市上浜町 1515
}

\begin{abstract}
In order to make a compositional design for glasses with large second- and third-order optical nonlinearity, second- and third-harmonic generation of various glasses were measured. For the glasses with large nonresonant type third-order optical nonlinearity, the nonlinear susceptibility increased in the glasses with high linear refractive index, high coordination number and high ionicity. Resonant type large third-order optical nonlinearity can be seen in semiconductor and metal microcrystals-doped glasses. In this case, the role of matrix glasses was significant on the third-order nonlinearity. For glasses with large second-order nonlinearity, external treatment was indispensable, thermal poling being effective to cause second-order optical nonlinearity.

[Received April 1, 2002]
\end{abstract}

Key-words : Optical nonlinearity, Homogeneous glasses, Microcrystals embedded glasses, Blue shift, Thermal poling

1. Introduction

$\mathbf{F}$ ROM the strong demand for the ultra high speed information transfer and processing, the photon-based system has a great potential to resolve this demand. In other words, photonics era is coming in near future, and the development of the photonic materials should be accelerated to catch up with the demand.

The application of nonlinear optical properties is one of the strong candidates to design photonics systems. The optical nonlinearity is expressed as follows by using polarization $(\vec{P})$ and intensity of incident light beam $(\vec{E})$,

$$
\vec{P}=\chi^{1)} \vec{E}+\chi^{2)} \vec{E} \cdot \vec{E}+\chi^{3)} \vec{E} \cdot \vec{E} \cdot \vec{E}+\cdots \cdots
$$

where $\chi^{(1)}$ is called optical linear susceptibility, $\chi^{(2)}$ and $\chi^{(3)}$ are second- and third-order optical nonlinear susceptibility, respectively. The $\chi^{(4)}, \chi^{(5)} \cdots \cdots$ are usually neglected because of the extremely small coefficient and the main roles are similar to the $\chi^{(2)}$ and $\chi^{(3)}$. The $\chi^{(2)}$ causes second harmonic generation, which is the generation of the light with half wavelength of the incident beam, generation of the light with summation and differentiation of the angular frequency of two incident beam light, and light rectification. On the other hand, $\chi^{(3)}$ causes third harmonic generation and similar light modulation. In addition to it, it causes optical Kerr effect and nonlinear optical absorption. The latter two effects are very important on the optical switching, memory and power limiting operation.

Glasses are promising materials for optical nonlinear application because of the high transparency, ease of fabrication into fibers and waveguides, high thermal and chemical durability, ease of doping, flexibility of composition and low costs of fabrication. Nevertheless, the studies of the glasses with large nonlinearity mainly started from 1980's. With respect to third-order nonlinearity, there are two ways' approaches. One is the homogeneous glasses, and the other is used as matrix of embedded semiconductors or metals microcrystals. Let me start from the studies for the glasses with large third-order nonlinearity.

\section{Third-order nonlinearity of glasses}

2.1 Third-order nonlinearity of homogeneous glasses The polarizability expressed in Eq. (1), the polarization $(\vec{P})$ and the intensity of incident light beam $(\vec{E})$ are the vectors, and the coefficient $\chi^{(3)}$ is tensor. Therefore, the magnitude of the coefficients for each functioning magnitude are not same, and, in specific, the coefficient of optical Kerr effect, which is important for optical switch, coupler and so on, is different from that of third harmonic generation. However, the glasses with a large coefficient generally have large coefficient for each third-order optical nonlinearity functioning, and thus third-harmonic generation (THG) measurements is very useful for screening the glasses for large optical Kerr effect as well as the determination of the magnitude THG among the several measurements technique such as degenerate four wave mixing and pump-probe method. ${ }^{1)}$ Lately, $Z$-scan technique has been extensively used for determining the sign as well as the magnitude of third-order optical nonlinearity. ${ }^{2)}$ Anyway, in order to design suitable composition for third-order optical nonlinearity, it should be decided to one technique to compare the magnitude. In this paper, I concentrate THG method for the compositional design since there are many available data for various glasses to be compared. The experimental set up is illustrated in Fig. 1, and typical THG datum is shown in Fig. 2. The so-called Maker fringe pattern is clearly seen in Fig. 2 caused by interference. The magnitude of THG corresponds to the magnitude of third-order optical nonlinearity. The $\chi^{(3)}$ values obtained by this method are tabulated in Table 1 . It is evident that $\chi^{(3)}$ values largely dependent on the composition. The largest $\chi^{(3)}$ is seen in chalcogenide series of glasses from $10^{-12}$ to $10^{-11}$ esu order, and those are 1000 times larger than that of $\mathrm{SiO}_{2}$ glass. In the chalcogenide glasses (NOG series), $\chi^{(3)}$ of As-S-Se glass is 1.4 $\times 10^{-11}$ esu which has been still the largest value in the homogeneous glasses without serious absorption. ${ }^{3)}$ In oxide glasses, tellurite glasses have a large nonlinearity. In the Table, it is basically said that the glasses with large refractive index have large third-order optical nonlinearity. For instance, the refractive index of chalcogenide glasses are over 2.0, while that of silica glass is 1.45 . As a matter of fact, 


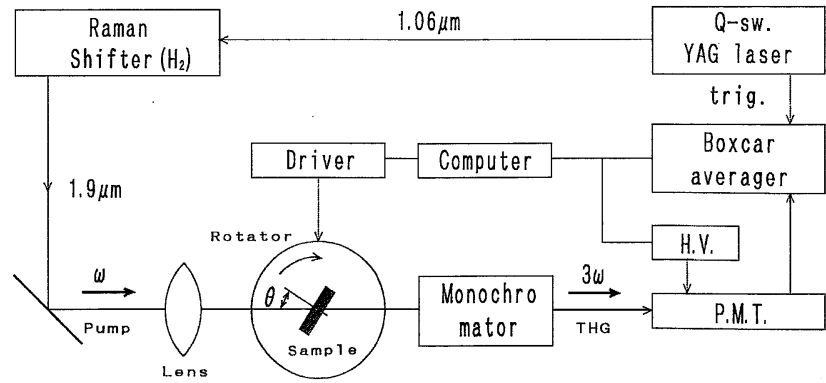

Fig. 1. Experimental set up for THG measurement.

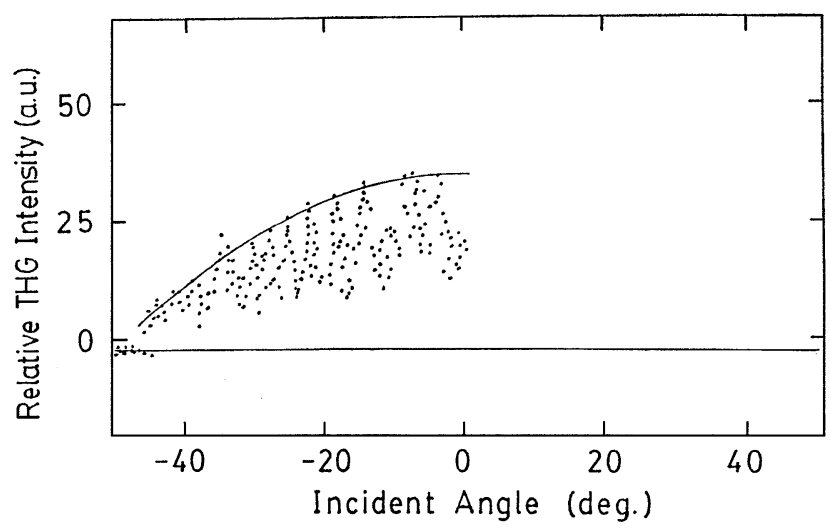

Fig. 2. Typical THG Maker fringe pattern of glasses.

Table 1. $\chi^{(3)}$ and Refractive Index of High-Index Glasses

\begin{tabular}{|c|c|c|}
\hline Glass composition & $x^{(3)}(e s u)$ & $\begin{array}{l}\text { refractive } \\
\text { index } \\
(633 \mathrm{~nm})\end{array}$ \\
\hline $\begin{array}{l}\text { (chalcogenide glasses) } \\
\mathrm{As}_{2} \mathrm{~S}_{3} \\
\text { NOG-1 (Ge-S) } \\
\text { NOG-2(Ge-As-S) } \\
\text { NOG-3(Ge-As-S) } \\
\text { NOG-4 (Ge-As-S-Se) } \\
\text { NOG-5 ( } \mathrm{As}-\mathrm{S}-\mathrm{Se})\end{array}$ & $\begin{array}{l}7.2 \times 10^{-12} \\
2.0 \times 10^{-12} \\
3.7 \times 10^{-12} \\
4.6 \times 10^{-12} \\
7.0 \times 10^{-12} \\
1.4 \times 10^{-11}\end{array}$ & $\begin{array}{l}2.53 \\
2.05 \\
2.22 \\
2.35 \\
2.36 \\
2.55\end{array}$ \\
\hline 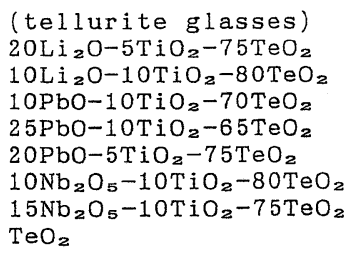 & $\begin{array}{l}4.3 \times 10^{-13} \\
8.0 \times 10^{-13} \\
2.8 \times 10^{-12} \\
3.7 \times 10^{-12} \\
3.6 \times 10^{-12} \\
1.2 \times 10^{-12} \\
9.6 \times 10^{-13} \\
1.4 \times 10^{-12}\end{array}$ & $\begin{array}{l}2.1 \\
2.2 \\
2.20 \\
2.27 \\
2.13 \\
2.18 \\
2.27 \\
2.239\end{array}$ \\
\hline $\begin{array}{l}\text { (gallate glasses) } \\
67 \mathrm{PbO} \cdot 33 \mathrm{GaO}_{1} \cdot 5 \\
10 \mathrm{TiO} \cdot 60 \mathrm{PbO}^{\circ} \cdot 30 \mathrm{CaO}_{1} \cdot 5 \\
\mathrm{RN}\end{array}$ & $\begin{array}{l}7.7 \times 10^{-13} \\
8.5 \times 10^{-13} \\
4.2 \times 10^{-13}\end{array}$ & $\begin{array}{l}2.260 \\
2.301 \\
2.30\end{array}$ \\
\hline $\begin{array}{l}\text { (germanate glasses) } \\
\mathrm{GeO}_{2} \\
2 \mathrm{ONa}_{2} \mathrm{O}-8 \mathrm{OGeO}_{2}\end{array}$ & $\begin{array}{l}1.0 \times 10^{-13} \\
1.3 \times 10^{-13}\end{array}$ & $\begin{array}{l}1.645 \\
1.678\end{array}$ \\
\hline $\begin{array}{l}\text { (silicate glasses) } \\
\mathrm{SiO}_{2} \\
\text { lead silicate glasses } \\
\mathrm{NbO}_{5} / 2-\mathrm{TiO}_{2}-\mathrm{Na}_{2} \mathrm{O}-\mathrm{SiO}_{2}\end{array}$ & $\begin{array}{l}2.8 \times 10^{-14} \\
4.4 \sim 7.5 \times 10^{-14} \\
0.7 \sim 5.8 \times 10^{-14}\end{array}$ & $\begin{array}{l}1.45 \\
1.7 \sim 2.02 \\
1.54 \sim 1.95\end{array}$ \\
\hline
\end{tabular}

there is semiemprical Miller (rule connecting $\chi^{(3)}$ and $\chi^{(1)}$, $\mathrm{as}^{4)}$

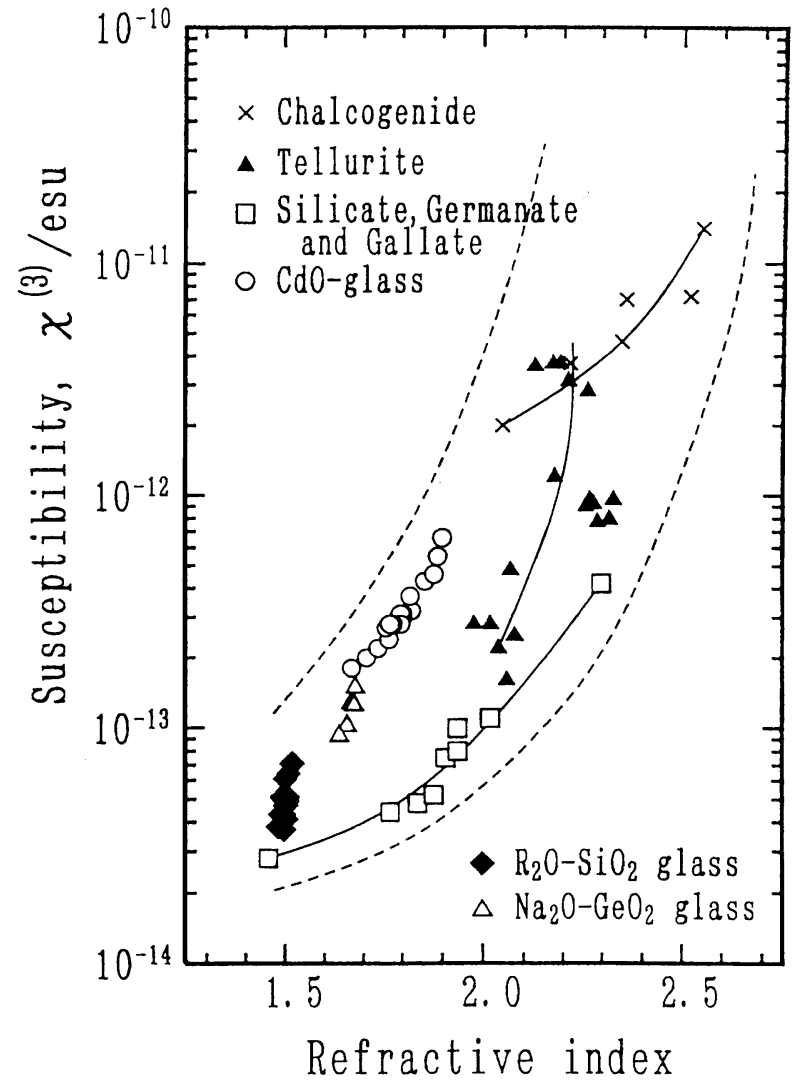

Fig. 3. $\chi^{(3)}$ of various glasses as a function of refractive index.

$$
\chi^{(3)}=\left(\chi^{(1)}\right)^{4} \times 10^{-10}(\mathrm{esu})
$$

The refractive index is proportional to $\chi^{(1)}$, and thus the high refractive index is expected to result in large third-order optical nonlinearity. Figure 3 shows the relationship between refractive index and $\chi^{(3)}$. As expected, $\chi^{(3)}$ basically increases with increasing refractive index, and thus the first basic concept for designing large $\chi^{(3)}$ glasses is choosing the glass composition with large refractive index. ${ }^{(5)}$ But, a close look for this figure, it is evident that the relationship is not so simple by expressing single curve, and the relationship shows the region of the $\chi^{(3)}$ versus refractive index. That is, the refractive index is not the only factor to determine $\chi^{(3)}$ and the simple curve can be obtained for similar glass systems. The $\chi^{(3)}$ is not the same between the glasses with the same refractive index when the basic system is different.

To investigate the influence of the glass microstructure on the third-order optical nonlinearity, the sodium germanate glass system was adopted. So-called germanium anomaly, which is change in coordination state of Ge depending on the sodium concentration, is caused in this system. Initially, Ge coordination number increases from 4 to 6 and then turned to 4 with nonbridging oxygens. Figure 4 shows $\chi^{(3)}$ as a function of $\mathrm{GeO}_{6}$ structure units. ${ }^{6)}$ From this figure, it is evident that $\chi^{(3)}$ depends on the $\mathrm{GeO}_{6}$ structure units concentration, and increases with increasing $\mathrm{GeO}_{6}$ units. The formation of nonbridging oxygen may cause hysteresis in the curve. It is evident that the coordination number significantly influence on $\chi^{(3)}$. The similar influence of the microstructure on $\chi^{(3)}$ was reported also by other groups. ${ }^{7)}$

The origin of third-order optical nonlinearity in homogeneous glasses is attributed to nonlinear electron polarization, and thus the ability of the deformation of va- 


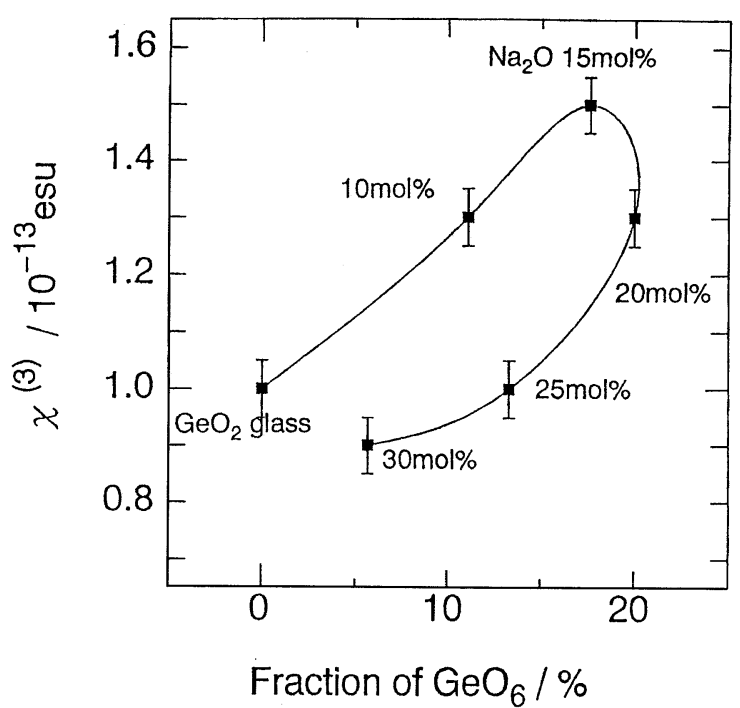

Fig. 4. $\chi^{(3)}$ of $\mathrm{Na}_{2} \mathrm{O}-\mathrm{GeO}_{2}$ glasses as a function of $\mathrm{GeO}_{6}$ fraction.

lence electron clouds are quite important. Therefore, the ionicity should be play an important role in the magnitude of $\chi^{(3)}$. For altering the ionicity, the formation of nonbridging oxygen atoms in the glasses are so simple and useful technique. Thus, we tried to add alkali ions in silica glass, and, for the exploring the magnitude of the influence, the elimination of nonbridging oxygen atoms keeping the same alkali content is necessary. Hence, we also prepared alumina containing glasses to eliminate nonbridging oxygens without reducing alkali content.8) In addition to the compositional designing, it is important to introduce the concept of hyperpolarizability $\left(\alpha^{(3)}\right)$, which express the contribution of each structural units to the total optical nonlinearity. For the incident beam $(E)$, the induced dipole moment of an ion $(p)$ is expressed as follows, ${ }^{9)}$

$$
p(t)=\alpha^{(1)} E_{\mathrm{loc}}(t)+\alpha^{(3)}(E(t))^{3 / 6}
$$

where $\alpha^{(1)}$ is ion's polarizability, $\alpha^{(3)}$ is ion's hyperpolarizability and $E_{\text {loc }}$ is local electric field, and

$$
\begin{aligned}
& \chi^{(3)}\left(-\omega ; \omega_{1}, \omega_{2}, \omega_{3}\right) \\
& \quad=L(\omega) L\left(\omega_{1}\right) L\left(\omega_{2}\right) L\left(\omega_{3}\right) \Sigma N_{i} \alpha^{(3)} / 24
\end{aligned}
$$

where $N_{i}$ is the number of $i$ ions , and $L(\omega)=\left(n_{0}^{2}+2\right) / 3$ for perfect ionic cubic crystal solids. For instance, $\alpha^{(3)} \mathrm{GeO}=2.0$ $\times 10^{-35} \mathrm{esu} \mathrm{cm}^{3} /$ unit and $\alpha^{(3)}{ }_{\mathrm{GeO} 6}=4.8 \times 10^{-35} \mathrm{esu} \mathrm{cm}^{3} /$ unit. Following this concept, the individual contribution of the structure unit can be calculated. In addition to the increase of refractive index in higher coordination state, the larger hyperpolarizability in higher coordination number increases third-order optical nonlinearity. Figure 5 depicts $\chi^{(3)}$ as a function of various alkali contents. It is evident that the $\chi^{(3)}$ increases as alkali content increases. The effect of alumina addition is shown in Fig. 6, and hyperpolarizability of each unit can be estimated as $\alpha^{(3)}{ }_{\mathrm{BO}}=0.43 \times 10^{-35}$ esu $\mathrm{cm}^{3} /$ ion (BO:bridging oxygen) and $\alpha^{(3)}{ }_{\mathrm{NBO}}=0.60 \times 10^{-35}$ esu $\mathrm{cm}^{3}$ /ion (NBO:nonbridging oxygen). Therefore, higher ionicity increases third-order optical nonlinearity. ${ }^{8}$ ) Although the number of nonbridging oxygen decreases as Al content increases, the $\chi^{(3)}$ increases. From the detail calculation, it is found to result from the large hyperpolarizability of cations such as $\mathrm{Al}^{3+}$.

Based on these above knowledge, we tried to manipulate to prepare the high $\chi^{(3)}$ materials, which could not be prepared by the conventional melting and quenching technique.

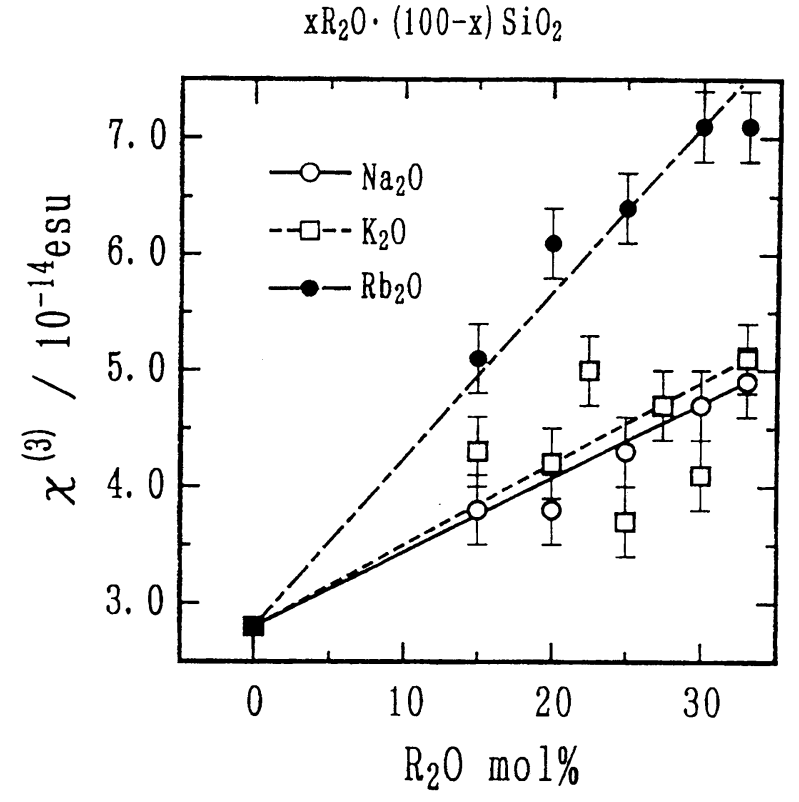

Fig. 5. $\chi^{(3)}$ as a function of alkali content in alkali silicate glasses.

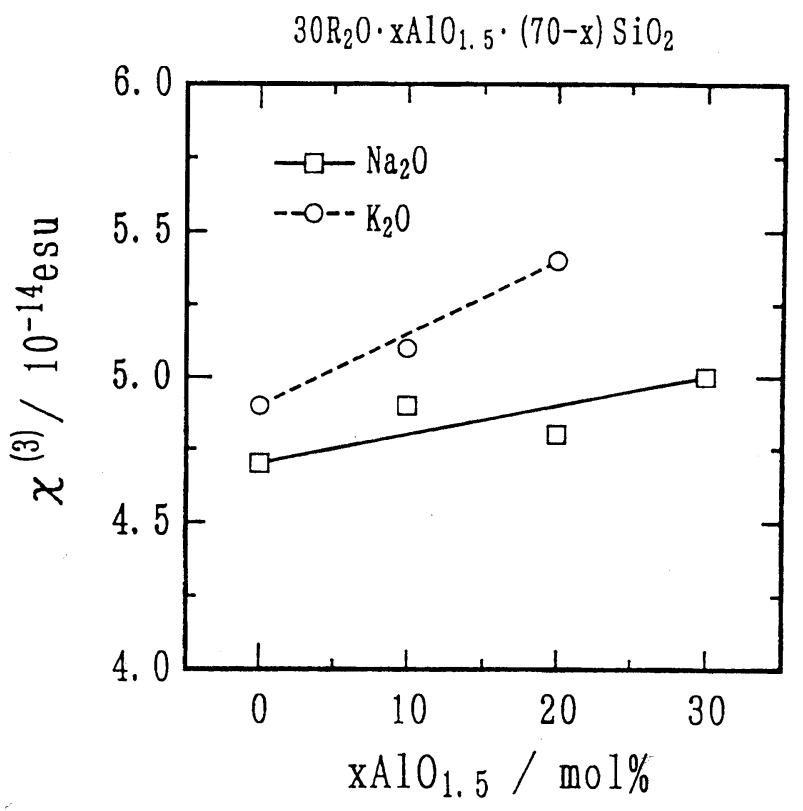

Fig. 6. $\chi^{(3)}$ as a function of alumina content in alkali alminosilicate glasses.

$\mathrm{PbO}-\mathrm{TiO}_{2}$ transparent amorphous bulk monolith can be prepared by mixing $\mathrm{Pb}\left(\mathrm{COOCH}_{3}\right)_{2}$ and $\mathrm{Ti}\left(\mathrm{OCH}\left(\mathrm{CH}_{3}\right)_{2}\right)_{4}$. After the heat treatment, the transparent $\mathrm{PbO}-\mathrm{TiO}_{2}$ bulk monoliths were obtained as shown in Fig. 7. The $\chi^{(3)}$ values obtained were in the order of $10^{-12} \mathrm{esu},{ }^{10)}$ corresponding to those of heavy metal oxides containing tellurite glasses.

2.2 Third-order nonlinearity of microcrystals embedded glasses

The size of microcrystals will be discussed here is below $100 \mathrm{~nm}$ in diameter, and this size corresponds to de Broglie wavelength of the materials. When the substances are confined in this size, quantum effect appears in the macroscopic properties such as optical properties. The enlargement of $\chi^{(3)}$ results from the confinement firstly reported by Jain and 


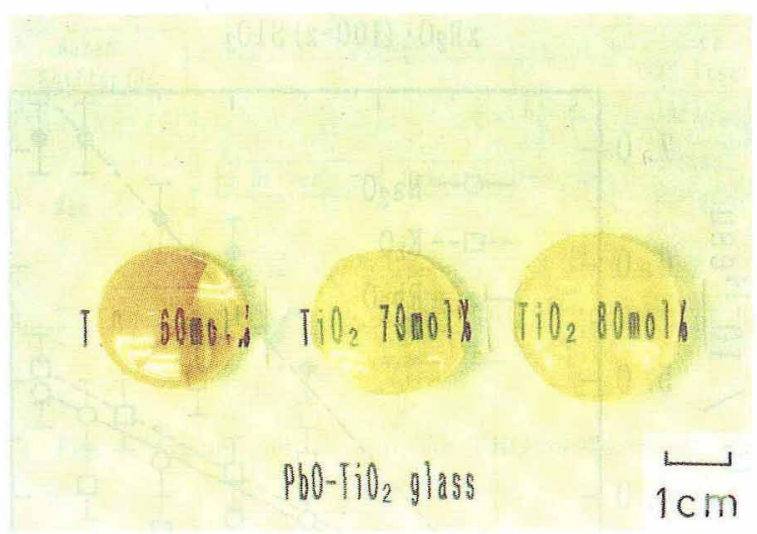

Fig. 7. Photographs of $\mathrm{PbO}-\mathrm{TiO}_{2}$ amorphous bulk monolith with large $\chi^{(3)}$ derived by sol-gel method.

Lind ${ }^{11)}$ from commercial filter glasses. Currently, the enlargement of $\chi^{(3)}$ compared with the bulk results from the strengthening of oscillation intensity and the concentration of incident light beam. In addition to it, the fast relaxation because of the confinement of electrons and holes is seen. Since microcrystals strongly tend to segregate due to the large surface energy, the matrix is indispensable to hold them. There are several kinds of substances are used, such as single crystals, polymers and glasses. Among them, glass has the advantage of high transparency, high thermal and chemical durability and so on as indicated the former section. On the other hand, the promising microcrystals for optical application are considered to be semiconductors and metals, which are activated electrons and holes and have surface plasmon resonant, respectively. We tried both microcrystals, but focused on the semiconductor microcrystals to avoid complexity. Furthermore, there are several techniques to prepare semiconductor microcrystals-doped glasses such as sol-gel, conventional melting and quenching, and rf-sputtering. We also tried these techniques to prepare the sample, but concentrated to rf-sputtering technique. The main advantages of $\mathrm{rf}$-sputtering method are low processing temperature, which is important to avoid oxidation and dissociation and ease for preparing semiconductor microcrystals-doped glasses by using complex target. By these points, rf-sputtering method makes it possible to prepare various semiconductor microcrystals-doped glasses such as $\mathrm{Si}, \mathrm{Ge}, \mathrm{GaAs}, \mathrm{CdTe}, \mathrm{CdSe}, \mathrm{CdS}, \mathrm{PbS}$ and $\mathrm{CuCl}$ containing glasses. The complex target is the simple technique that semiconductor chips putting on the matrix materials. Say, CdSe chips are put on silica glass for the preparing $\mathrm{CdSe}$-doped $\mathrm{SiO}_{2}$ glass thin film. Figure 8 shows transmission electron micrograph picture of the microcrystals in the glass matrix.

Figure 9 shows X-ray diffraction (XRD) patterns of the $\mathrm{CdTe}$-doped $\mathrm{SiO}_{2}$ glasses. From this figure, it is evident that the diffraction lines gradually become sharper as the relative surface area ratio increases. The percent of the relative surface area ratio of the semiconductor chips in the target are (a) $3.1 \%$, (b) $4.2 \%$, (c) $6.3 \%$ covering of the center of the target, and (d) $2.0 \%$ covering $3.0 \mathrm{~cm}$ away from the center of the target where just upon the magnet. This means basically the particle size increases with increasing relative surface area ratio and the position of the chips on the target are also quite important. When the quantum size effect appears, the optical absorption edge shift toward shorter wavelength, which is so-called blue shift resulting from dissociation of the energy band. Figure 10 shows the blue shift of the opti-

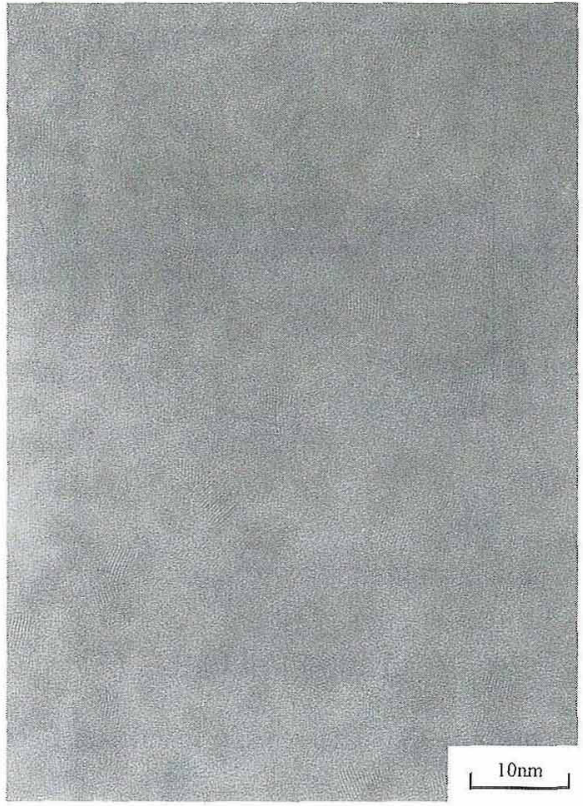

Fig. 8. Photograph of the semiconductor mycrocrystals in glass matrix.

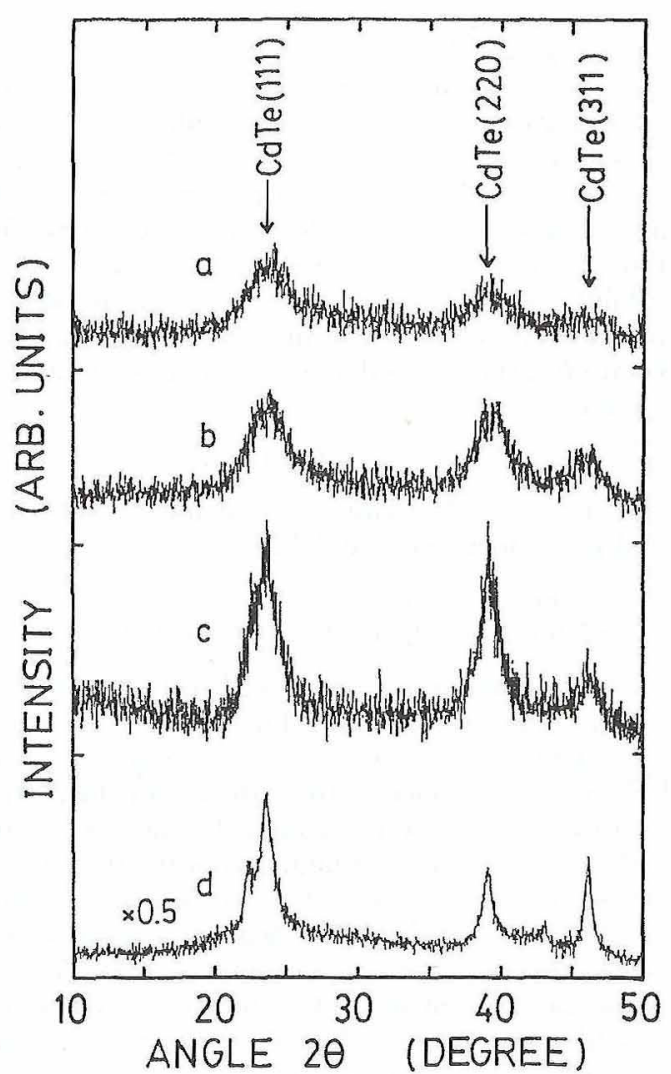

Fig. 9. XRD patterns of the CdTe microcrystals in $\mathrm{SiO}_{2}$ glass matrix with various relative surface area ratio of the CdTe chips on $\mathrm{SiO}_{2}$ plate as the targets.

cal absorption edge for CdTe embeded glasses. As the microcrystal size decreases, the absorption edge decreases. This means there is the quantum size effect of the films. There are two types of the quantum size effect. One is the 


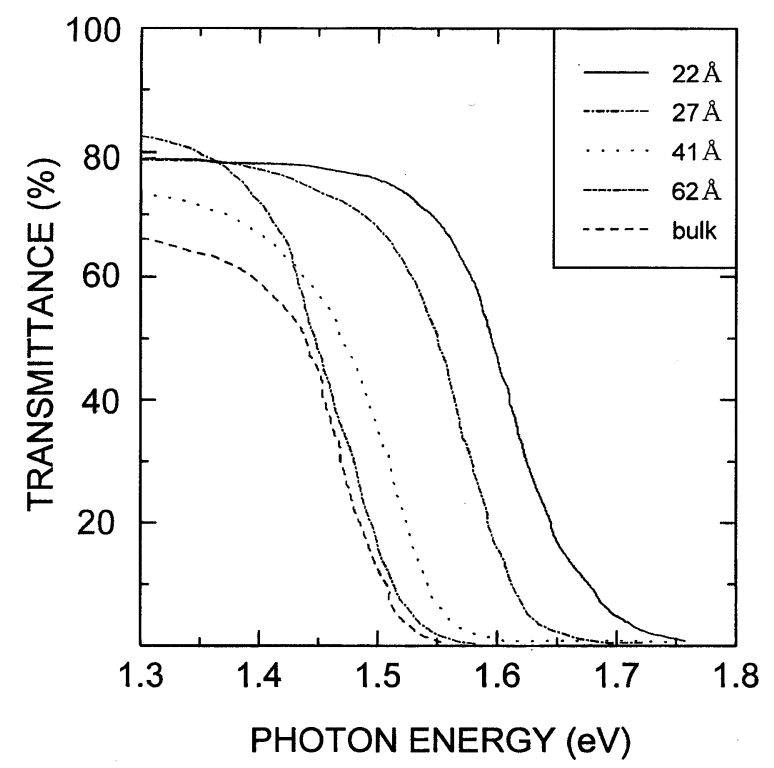

Fig. 10. Blue shift of the optical absorption edge for the glass thin fims with various microcrystals size for CdTe microcrystals embedded glasses.

exciton confinement effect, and the other is electron-hole independent confinement effect. The effect depends on the ratio of exciton Bohr radius $\left(r_{\mathrm{B}}\right)$ and microcrystals $(R)$ formed. When $r_{\mathrm{B}} / R<2$, the blue shift $(\Delta E)$ is expressed as

$$
\Delta E=\pi^{2} \hbar^{2} / 2 \mathrm{MR}^{2}
$$

where,

$$
M=m_{\mathrm{e}}+m_{\mathrm{h}}
$$

$M$ is called translational mass, $m_{\mathrm{e}}$ and $m_{\mathrm{h}}$ are effective mass of electron and hole, respectively. That is the exciton confinement. On the other hand, when $r_{\mathrm{B}} / R>4$, electron-hole independent confinement is expected to appear as

$$
\Delta E=\pi^{2} \hbar^{2} / 2 \mu R^{2}
$$

where

$$
1 / \mu=1 / m_{\mathrm{e}}+1 / m_{\mathrm{h}}
$$

$\mu$ is called reduced mass. Figure 11 depicts the theoretical curves and experimental data for CdSe microcrystals-doped $\mathrm{SiO}_{2}$ films. For exciton confinement such as $\mathrm{CuCl}$-doped glasses well fits Eq. (5), and matrix has no influence on the quantum confinement effect. ${ }^{12)}$ However, the experimental results for CdSe-doped films, which should follow Eq. (7), clearly deviates from the theoretical curve. In order to explain this deviation, Kayanuma' equation ${ }^{13)}$ is needed to be introduced,

$$
\Delta E=\pi^{2} \hbar^{2} / 2 \mathrm{~m} R^{2}-1.786 \mathrm{e}^{2} / \varepsilon R-0.248 R_{\mathrm{y}}^{*}
$$

where $\varepsilon$ is dielectric constant and $R_{\mathrm{y}}{ }^{*}$ is effective Rydberg constant. In this equation, $\varepsilon$ should be varied depending on the microcrystal size, and thus Haken potential ${ }^{15}$ is needed to be taken into consideration, which is

$$
\begin{aligned}
& 1 / \varepsilon\left(R^{*}\right)=1 / \varepsilon_{\infty}-\left(1 / \varepsilon_{\infty}-1 / \varepsilon_{0}\right) \\
& \times \frac{1-\left(\exp \left(-R^{*} / \rho_{1}\right)+\exp \left(-R^{*} / \rho_{2}\right)\right)}{2}
\end{aligned}
$$

where $\varepsilon_{\infty}$ and $\varepsilon_{0}$ are the dielectric constant at frequency in- finite and zero, respectively, $R^{*}$ is the mean distance of electron and hole, and $\rho_{1}$ and $\rho_{2}$ are the polaron radius of ele-

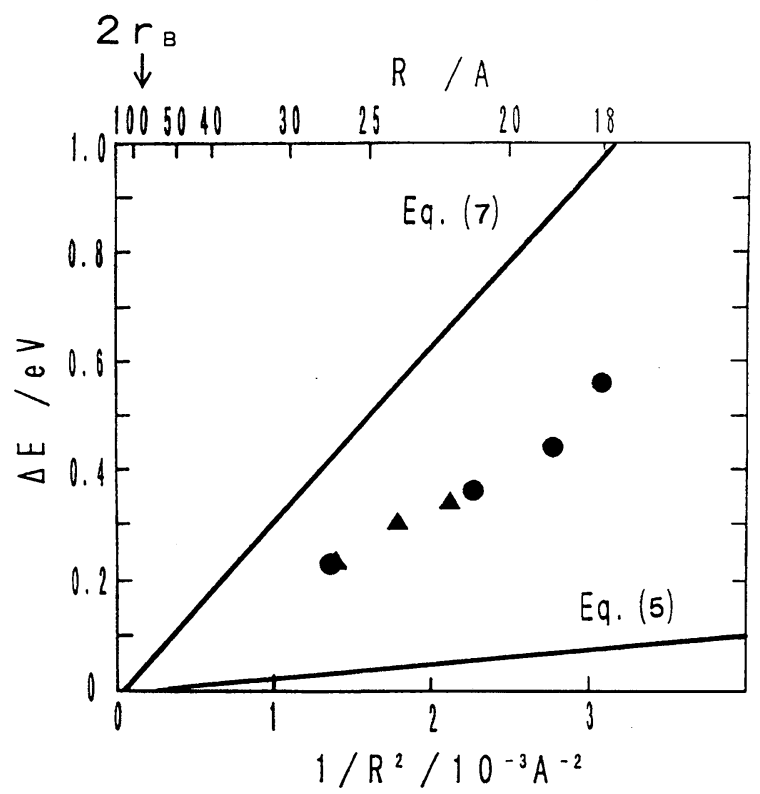

Fig. 11. Theoretical curves for quantum confinement and the experimental data.

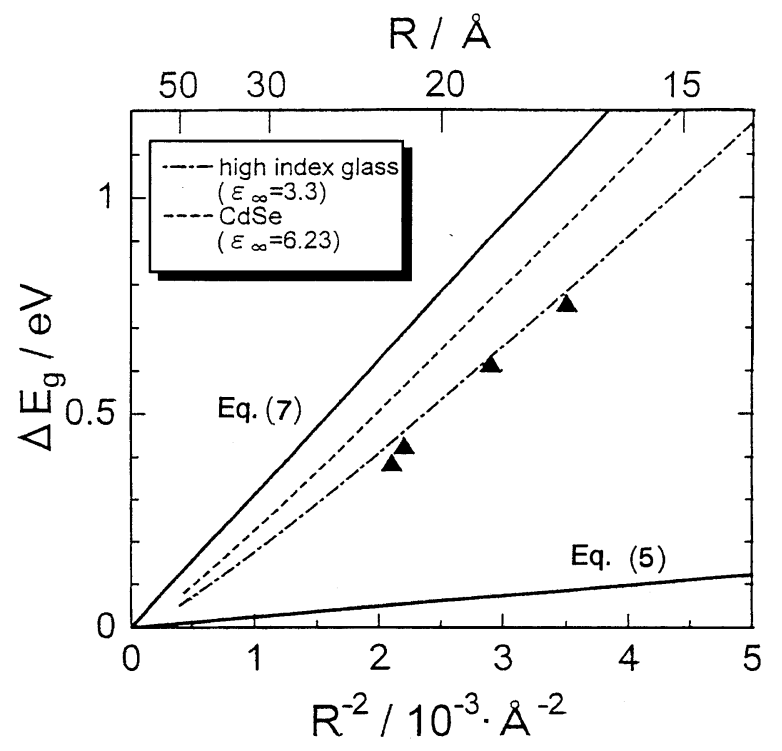

Fig. 12. Theoretical curves using Eqs. (9) and (10) and the experimental data.

ctron and hole, respectively. Figure 12 shows the plot of the experimental blue shift and new theoretical curve using Eqs. (9) and (10). Two theoretical curves are the one of using $\varepsilon_{\infty}$ of semiconductor doped and the one of using that of a matrix glass. It is evident that the experimental data well fit by using $\varepsilon_{\infty}$ of the matrix glass, and thus it is found that there is important role of matrix glass on the quantum size effect through the dielectric constant. Figure 13 shows the influence of matrix on the amount of blue shift.

With respect to third-order nonlinearity, the $\chi^{(3)}$ was evaluated as large as $10^{-8}$ esu order ${ }^{14)}$ even though the thickness is quite thin and relaxation time was as fast as about 50 to 60 ps compared with bulk crystal. 


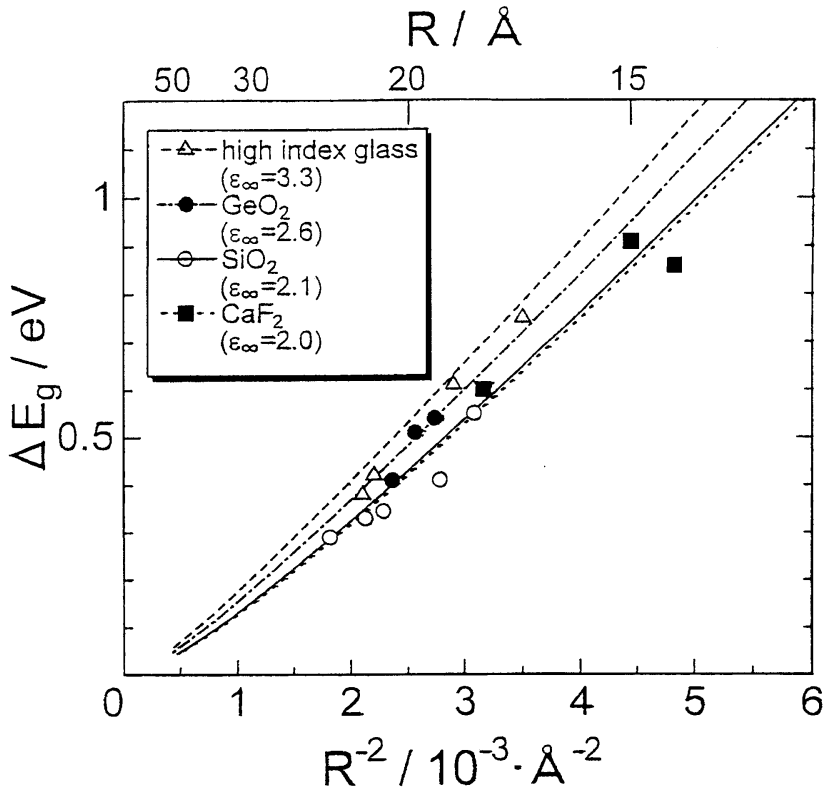

Fig. 13. Influence of the matrix on the amount of the blue shift.

3. Second-order nonlinearity of thermally poled glasses Second-order optical nonlinearity causing such as second harmonic generation ( $\mathrm{SHG}$ ) is not theoretically seen in the materials with centro-symmetry in the length of optical region. Therefore, it had been considered glasses should not have second-order optical nonlinearity, until SHG was observed in $\mathrm{Ge}$-doped $\mathrm{SiO}_{2}$ glass fibers. ${ }^{16)}$ The $\mathrm{SHG}$ from Gedoped $\mathrm{SiO}_{2}$ is interpreted by the defects of $\mathrm{Ge}$ such as $\mathrm{Ge}$ E'center.

On the other hand, Myers et al. ${ }^{17)}$ reported various intensity of $\mathrm{SHG}$ from $\mathrm{SiO}_{2}$ derived by various raw materials after electrically poled at near $300^{\circ} \mathrm{C}$. We then considered that the difference in $\mathrm{OH}^{-}$concentration may result in the difference in SHG intensity, and thus we prepared various $\mathrm{SiO}_{2}$ glasses derived through various routes such as sol-gel, VAD (vapor axial deposition) and conventional melting and quenching technique. Figure 14 shows SHG intensity as a function of $\mathrm{OH}^{-}$concentration after poled by $3 \mathrm{kV}$ at $300^{\circ} \mathrm{C}$. As one can see, SHG clearly depends on $\mathrm{OH}^{-}$concentration and drastically increases with increasing $\mathrm{OH}^{-}$concentration.

Then, we tried to find out other SHG system, in specific, in silicate system, since we found the addition of $\mathrm{OH}^{-}$cause large SHG intensity in $\mathrm{SiO}_{2}$ glass. The $\mathrm{TiO}_{2}-\mathrm{SiO}_{2}$ system has high melting point and is hardly melted by the conventional melting method. Thus, we added alkali ions for reducing melting point, and we added two kinds of alkali oxides to cause so-called mixed alkali effect to maintain high insulation property. In $\mathrm{K}_{2} \mathrm{O}-\mathrm{Cs}_{2} \mathrm{O}-\mathrm{TiO}_{2}-\mathrm{SiO}_{2}$ glass system; $\mathrm{SHG}$ was observed after thermal poling, and no SHG was observable in $\mathrm{TiO}_{2}$-free glass. Thus, it is noted that $\mathrm{TiO}_{2}$ was relating to SHG center of the glasses. Furthermore, it is found that SHG depends on the $\mathrm{TiO}_{2}$ content, and the maximum of SHG is observed at $\mathrm{TiO}_{2}=25 \mathrm{~mol} \%$ as shown in Fig. 15 . The coordination number of $\mathrm{Ti}^{4+}$ is pointed out $4,5,6$ and centro-symmetry is lost at 5 coordinated structure. Hence, we measured the coordination number by XANES of Ti by synchrotron orbital radiation technique. As a result, the highest concentration of 5 coordinated $\mathrm{Ti}^{4+}$ was observed at $\mathrm{TiO}_{2}=25 \mathrm{~mol} \%$. ${ }^{18}$

SHG was observed in other silicate glasses containing, for example, $\mathrm{PbO}, \mathrm{Nb}_{2} \mathrm{O}_{5}, \mathrm{Ga}_{2} \mathrm{O}_{3}$. $\mathrm{SHG}$ was also observed in

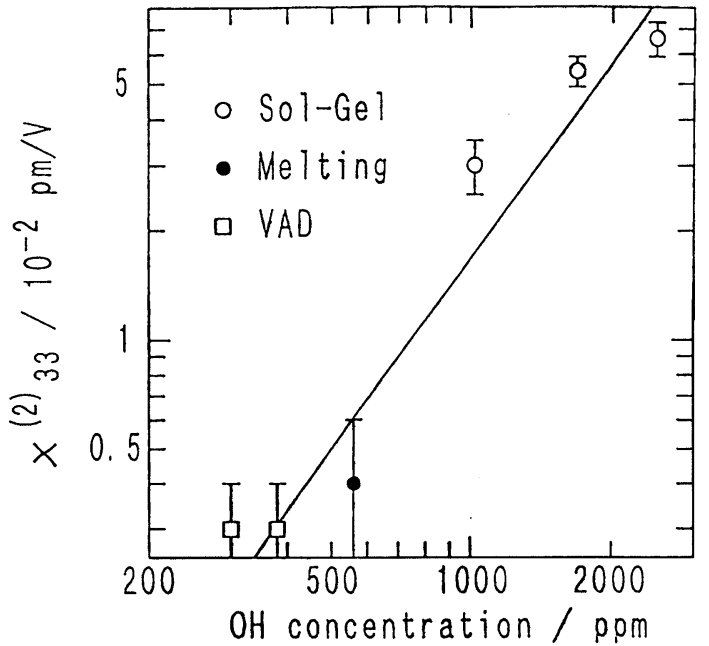

Fig. 14. Second-order nonlinear susceptibility of $\mathrm{SiO}_{2}$ glasses as a function of $\mathrm{OH}^{-}$concentration.

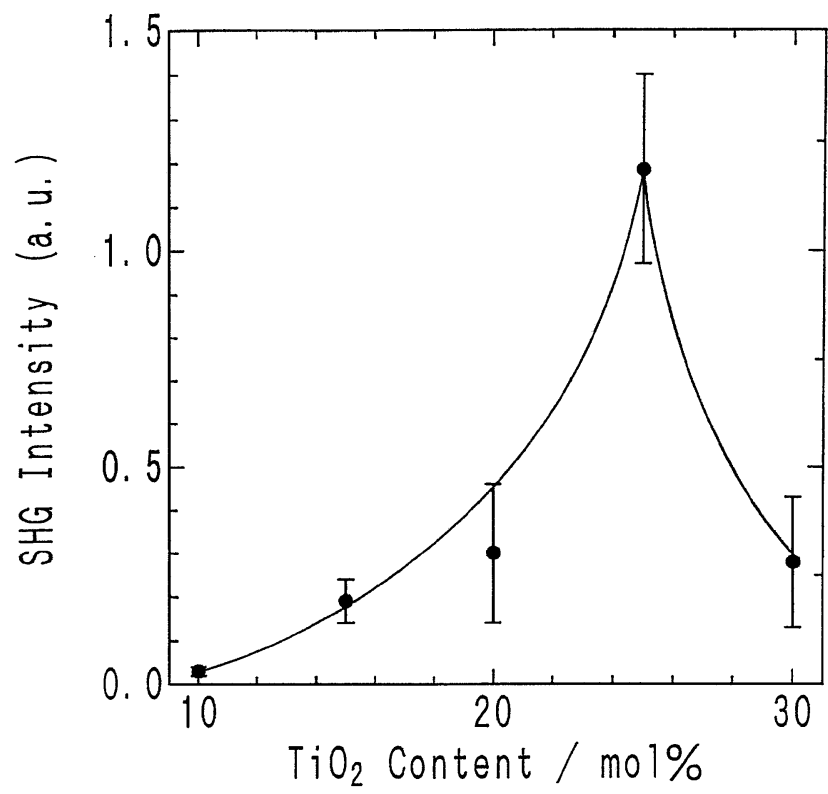

Fig. 15. $\mathrm{SHG}$ intensity of $\mathrm{K}_{2} \mathrm{O}-\mathrm{Cs}_{2} \mathrm{O}-\mathrm{TiO}_{2}-\mathrm{SiO}_{2}$ glasses as a function of $\mathrm{TiO}_{2}$ content.

various tellurite glasses. ${ }^{19)}$

\section{Conclusion}

The basic researches for compositional design of the glasses with large second- and third-order optical nonlinearity have been carried out. With respect to third-order optical nonlinearity, there are two categories in the glasses. One is the homogeneous glasses and the other is microcrystals embedded glasses. For the compositional designing for the homogeneous glasses with large third-order nonlinearity, large refractive index, high coordination state and high ionicity are found to be important. For microcrystals embedded glasses, glasses play an role not only as the transparent matrix but also as active media through the dielectric constant of the microcrystals in the case of the semiconductor microcrystals with large Bohr exciton radius. With respect to second-order optical nonlinearity, introducing the addi- 
tives breaking up the centro-symmetry such as $\mathrm{OH}^{-}$and 5coordinated $\mathrm{Ti}^{4+}$ is effective to cause $\mathrm{SHG}$.

\section{References}

1) For example, "Yuuki Hisenkei Kougaku Zairyo no Kaihatsu to Oyo," Ed. by Nakanishi, H., Kobayashi, T., Nakamura, A. and Umegaki, S., CMC,Tokyo (2001).

2) Hashimoto, T., Yamamoto, T., Kato, T., Nasu, H. and Kamiya, K., J. Appl. Phys., 90, 533-37 (2001).

3) Nasu, H., Ibara, Y. and Kubodera, K., J. Non-Cryst. Solids, 110, 229-34 (1989).

4) Chang, T. Y., Opt. Eng., 20, 220-31 (1981).

5) Nasu, H., Matsuoka, J. and Kamiya, K., J. Non-Cryst. Solids, 178, 23-30 (1994).

6) Sugimoto, O., Nasu, H., Matsuoka, J. and Kamiya, K., J. NonCryst. Solids, 161, 118-22 (1993).

7) Terashima, K., Hashimoto, T., Uchino, T., Kim, S.-H. and Yoko, T., J. Ceram. Soc. Japan, 104, 1008-14 (1996).

8) Nasu, H., Sugimoto, O., Matsuoka, J. and Kamiya, K., J. NonCryst. Solids, 182, 321-27 (1995).

9) Borrelli, N. F. and Hall, D. W., "Optical Properties of Glass,"
Ed. by Uhlmann, D. R. and Kreidl, N. J., Am. Ceram. Soc., Columbus, OH (1991) p. 87.

10) Katagiri, Y., Nasu, H., Matsuoka, J. and Kamiya, K., J. Am. Ceram. Soc., 77, 5773-78 (1994).

11) Jain, R. K. and Lind, R. C., J. Opt. Soc. Am., 73, 647-53 (1983).

12) Nasu, H., Yamamoto, T., Iwano, T., Hashimoto, T. and Kamiya, K., J. Ceram. Soc. Japan, 106, 1037-39 (1998).

13) Kayanuma, Y., Phys. Rev., B, 38, 9797-805 (1988).

14) Haken, H., Nuovo Cimento, 10, 1230-37 (1956).

15) Yumoto, J., Shinojima, H., Uesugi, T., Tsunetomo, K., Nasu, H. and Osaka, Y., Appl. Phys. Lett., 57, 2393-95 (1990).

16) Sasaki, Y. and Ohmori, Y., Appl. Phys. Lett., 39, 466-68 (1981).

17) Myers, R. A., Mukherjee, N. and Bruech, S. R. J., Opt. Lett., 16, 1732-34 (1991).

18) Nasu, H., Kurachi, K., Mito, A., Okamoto, H., Matsuoka, J. and Kamiya, K., J. Non-Cryst. Solids, 181, 83-86 (1995).

19) Narasaki, A., Tanaka, K., Hirao, K. and Soga, N., J. Am Ceram. Soc., 81, 2735-37 (1998).

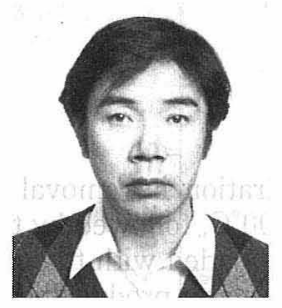

Hiroyuki Nasu graduated in Faculty of Engineering, Kyoto University in 1978, and completed graduate school of Kyoto University, in 1983 and received $\mathrm{Ph}$. D. in 1983. Then, he worked at Department of Materials Science and Engineering, University of California at Los Angeles (UCLA) as postdoctral fellow from 1983 to 1986. He worked at Department of Electric and Electronic Engineering, Hiroshima University as research associate from 1986 to 1989. Now he worked at Department of Chemistry for Materials, Faculty of Engineering, Mie University since 1989 as associate professor. 